\title{
Tecnologias digitais da informação e comunicação na aprendizagem baseada em problemas no ensino superior
}

\section{Digital information and communication techhnologies in problem based learning in higher education}

\author{
Aécio Silva Júnior ${ }^{1 *}$, Sindiany Suelen Caduda dos Santos ${ }^{1}$
}

\begin{abstract}
RESUMO
Este artigo objetiva descrever as experiências sobre a integração das Tecnologias Digitais da Informação e Comunicação (TDICs) à metodologia da Aprendizagem Baseada em Problemas (ABP), no módulo de Ciências da Vida, durante o ensino remoto emergencial, na Universidade Federal de Sergipe. Foram consideradas as experiências de quatro turmas de estudantes de cursos de Ciências Agrárias, do Campus do Sertão, no módulo de Ciências da Vida. Utilizou-se das interfaces digitais durante as etapas da ABP: Jamboard $囚$, Padlet, Google Forms e Kahoot. Na produção dos dados, foram utilizadas as evidências de aprendizagem observadas durante a execução das atividades realizadas pelos estudantes. Os resultados apontaram potencialidades do ensino personalizado com o uso dos recursos digitais e promoção da aprendizagem dos discentes e mostrou que as TDICs facilitaram a construção de conhecimentos quanto aos conceitos de Ciências da Vida. Frente ao retorno do ensino presencial, no pós-pandemia da COVID-19, espera-se que este trabalho inspire educadores, no tocante às discussões sobre a necessária e permanente articulação entre TDICs, metodologias ativas e personalização do ensino.
\end{abstract}

Pal avras-chave: Ensino de ciências da vida; Metodologias ativas; ABP; Universidade Federal de Sergipe.

\begin{abstract}
This article aims to describe the experiences on the integration of Digital Information and Communication Technologies (Tdics) to the Problem-Based Learning (PBL) methodology, in the Life Sciences module, during emergency remote education, at the Federal University of Sergipe. The experiences of four classes of students of Agrarian Sciences courses at the Sertão Campus were considered in the Life Sciences module. Digital interfaces were used during the PBL stages: Jamboard®, Padlet, Google Forms and Kahoot. In the production of the data, we used the evidence of learning observed during the execution of the activities carried out by students. The results showed potentialities of personalized teaching with the use of digital resources and promotion of students' learning and showed that Tdics facilitated the construction of knowledge regarding the concepts of Life Sciences. In view of the return of classroom teaching, in the postpandemic COVID-19, it is expected that this work will inspire educators, in terms of the discussions on the necessary and permanent articulation between Tdics, active methodologies and customization of teaching.
\end{abstract}

Keywords: Teaching of life sciences; Active Methodologies; PBL; Federal University of Sergipe.

\footnotetext{
${ }^{1}$ Universidade Federal de Sergipe, Campus do Sertão 1. *E-mail: aeciojuniormedvet@ gmail.com
} 


\section{INTRODUÇÃO}

Um dos maiores desafios no ensino superior é encontrar formas de promover a aprendizagem significativa dos graduandos, de forma inovadora, utilizando Tecnologias Digitais da Informação e Comunicação - TDICs (BERGONSI, 2020). Apesar disso, frente à pandemia da COVID-19, os docentes do Campus do Sertão, da Universidade Federal de Sergipe (UFS), precisaram repensar o formato das aulas e estabelecer caminhos de condução das etapas da Aprendizagem Baseada em Problemas, a partir do uso das TDICs, durante o ensino remoto emergencial.

A Aprendizagem Baseada em Problemas (PBL - Problem Based Learning), está pautada na ideia de que o estudante está no centro do processo de ensino e aprendizagem, que o professor é mediador (BERBEL, 2011) e que princípios como autonomia, protagonismo, problematização, reflexão da realidade e inovação, são priorizados na formação dos sujeitos. Nessa perspectiva, defende-se a importância da criação de possibilidades para que a aprendizagem aconteça de modo eficaz.

Enxerga-se esta criação de possibilidades como personalização (HORN; STAKER, 2015). Os autores destacam que, ao personalizar o ensino, o docente pode utilizar as diversas interfaces das TDICs, para promover espaços de aprendizagem diversificados, atendendo às necessidades dos estudantes. $\mathrm{O}$ uso das TDICs se destaca à medida que estas são capazes de transformar as relações com o saber, mediante as diversas possibilidades de aprendizado que oferecem (KENSKI, 2012; BACICH; MORAN, 2018). Nesse sentido, é possível, ao aluno, traçar a sua rota de construção do conhecimento e compreensão dos conteúdos, ao mesmo tempo em que o professor coleta evidências de aprendizagem e reflete sobre processos avaliativos.

É indubitável que as TDICs utilizadas na contemporaneidade promoveram significativas transformações no desenvolvimento histórico-humano. Por meio delas, pessoas do mundo inteiro interconectam-se através das redes globais de comunicação. Quando se fala da relação tecnologia e educação, Lévy (1999, p.57), trata sobre a ideia de ciberespaço, o qual também é chamado de rede, e constitui "o novo meio de comunicação que surge da interconexão mundial dos computadores [...]”. Para Lévy (1999, p. 157), “o ciberespaço suporta tecnologias intelectuais que amplificam, exteriorizam e modificam numerosas funções cognitivas humanas: memória... 
imaginação... percepção... raciocínio". Diante deste ciberespaço, Lévy (2009) reforça que os processos tradicionais de aprendizagem estão obsoletos. Logo, o uso de TDICs junto às metodologias ativas é um dos caminhos para promover a aprendizagem significativa.

Na UFS, durante o ensino remoto emergencial, o módulo de Ciências da Vida foi construído de maneira a permitir aos estudantes calouros dos cursos das Ciências Agrárias, a construção do conhecimento com base no acesso às diversas estratégias metodológicas, com uso de TDICs, sem deixar de seguir os princípios da Aprendizagem Baseada em Problemas. Por consequência, a ABP ganhou um formato personalizado no módulo de Ciências da Vida.

Diante das necessárias mudanças didático-pedagógicas no ensino superior, das transformações culturais quanto às formas de ensinar e aprender, impostas pela pandemia da COVID-19, e da importância de se refletir sobre a personalização na ABP, este artigo emergiu da necessidade de divulgar experiências do ensino superior que revelam como as TDICs podem potencializar ainda mais os processos de ensino e aprendizagem, articuladas às metodologias ativas.

Isto posto, objetiva-se descrever as experiências sobre a integração das Tecnologias Digitais da Informação e Comunicação (TDICs) à metodologia da Aprendizagem Baseada em Problemas (ABP), no módulo de Ciências da Vida, durante o ensino remoto emergencial, na Universidade Federal de Sergipe. Para tanto, serão apresentadas as experiências teórico-práticas referentes ao tema "ecologia", com base no uso de TDICs, durante a execução das etapas da ABP no módulo de Ciências da Vida. Nesse viés, será descrito como as interfaces Jamboard®, Padlet, Google Forms e Kahoot têm permitido a criação de espaços colaborativos e interativos, facilitando a aprendizagem e a construção de conhecimentos sobre os sistemas biológicos.

\section{METODOLOGIAS ATIVAS E O USO DE TECNOLOGIAS DIGITAIS DA INFORMAÇÃO E COMUNICAÇÃO}

Em meio à necessidade de focar na aprendizagem centrada no estudante, inúmeras metodologias ativas têm sido utilizadas no ensino superior. É possível citar a Aprendizagem Baseada em Projetos (Project-Based Learning - PBL); a Aprendizagem por meio de jogos (Game-Based Learning - GBL); o método de estudo de caso ou discussão e solução de casos (Teaching Case); a aprendizagem em equipe (Team-Based Learning - TBL); entre outras. 
No tocante à Aprendizagem Baseada em Problemas (ABP, ou PBL em inglês), esta teve início com a sua implementação no ensino superior na Faculdade de Medicina da McMaster University, em Hamilton (Ontário, Canadá), no fim dos anos 1960, através de Howard Barrows e seus colaboradores. Após isso, começou a ser a plicada em outras áreas acadêmicas e profissionais como ciências da saúde, matemática, economia, ciências sociais e outras. Hodiernamente, a metodologia é aplicada em todos os níveis de ensino e sua evolução, assim como a de outros métodos para o desenvolvimento de competências, culminou em uma filosofia de ensino, uma maneira de compreender a educação e um estilo de aprendizagem (ZABALA; ARNAU, 2020).

Entre as múltiplas referências sobre a Aprendizagem Baseada em Problemas, há vários autores que definem a ABP de forma semelhante. De modo geral, ela é conceituada como uma metodologia de aprendizagem pautada no uso de situações-problema que constituem ponto de partida para a aplicação e integração de novos conhecimentos. Ou seja, uma aprendizagem focada no discente, em que os professores são tutores do processo de produção do conhecimento. A metodologia da $\mathrm{ABP}$ entende que para as informações se tornarem conhecimento, é preciso refletir a respeito do conteúdo a ser aprendido (BARROWS, 1986; BERBEL, 2011).

A ABP ocorre em etapas que abrangem passos basilares para a efetivação da aprendizagem ativa. Ao deparar-se com o problema elaborado previamente por uma equipe de especialistas, o grupo de estudantes de cerca de oito a dez discentes, chamado de grupo tutorial, escolherá o coordenador e secretário do grupo. Na sequência, é feita a leitura e discussão prévia do caso, para identificação e esclarecimento de conceitos. A partir desse momento, os estudantes devem fazer um inventário dos conhecimentos existentes acerca do problema proposto, fazendo o levantamento de questões. Posteriormente, um brainstorm é realizado com o propósito de explicar as questões levantadas, por meio da elaboração de hipóteses. Todas essas ideias deverão ser organizadas e sistematizadas de modo que as possíveis respostas conduzam à identificação das informações necessárias para a resolução do problema. Assim, são formulados os objetivos de aprendizagem, os quais conduzirão os estudos dos estudantes no tempo determinado pelo professor. Todas essas etapas compõem a abertura da ABP e são essenciais para que os discentes continuem os estudos de forma independente, por meio da pesquisa, da busca de informações em literatura científica e da elaboração de materiais escritos e ou participação em outras propostas pedagógicas. Essa busca e 
sistematização deverá ser compartilhada com o grupo tutorial no momento do fechamento do problema, em uma etapa chamada de reconceitualização e esclarecimento. Por fim, no momento da avaliação, o grupo tutorial verifica se os objetivos foram atendidos e se novas hipóteses surgiram a partir de toda construção (BERBEL, 1998; ZABALA; ARNAU, 2020). Salienta-se que após o estudo de um problema poderão surgir outros, resultantes inclusive de desdobramentos do primeiro, mas percebidos pelos estudantes somente com o estudo aprofundado deste (BERBEL, 1998).

As etapas da $\mathrm{ABP}$ como apresentadas acima exigem que o professor, chamado de tutor, reflita sobre como cada etapa poderá engajar os estudantes com uso de estratégias metodológicas que produzam efeitos sobre o ensino e a aprendizagem. Destarte, ao considerar o contexto contemporâneo em que as transformações na educação são evidentes, que a sala de aula não é a mesma, que estudantes e professores mudaram e que os espaços de aprendizagem são também virtuais (MORAN, 2015), não se pode negar a importância das TDICs para personalizar e potencializar o ensino na ABP. De acordo com Schuck, Neuenfeldt e Kalkmann (2019), as TDICs atingem diretamente o ambiente escolar e acadêmico conduzindo-o a um novo tempo, ocasionando profundas mudanças no ensino e aprendizagem.

Do ponto de vista teórico, ao divulgar o uso de recursos digitais com o foco educacional, recorrentemente o maior destaque está na capacidade que as interfaces possuem de motivar os estudantes. Existem na literatura científica diversas pesquisas quanto aos benefícios de jogos didáticos e recursos digitais voltados para a educação. No âmbito da motivação, os recursos digitais apresentam potencial de promover entretenimento e diversão aos usuários, ao mesmo tempo que provém ambientes com alta interatividade e dinamismo para incentivar o aprendizado (HSIAO, 2017). Para além disso, as interfaces são capazes de auxiliar os discentes a desenvolverem uma série de competências e estratégias profissionais e humanísticas (GROS, 2003).

Ao considerar que as TDICs têm participação massiva no cotidiano dos alunos, na vida social ou no contexto educacional, existe a possibilidade de utilizá-las para tornar a aprendizagem significativa. Desse modo, é possível mobilizar os estudantes para a construção do próprio conhecimento (VIANA; LOZADA, 2020).

Dabbagh, Fake e Zhang (2019) executaram uma pesquisa em universidades dos Estados Unidos (EUA) e puderam constatar que é de suma importância para os alunos o uso de dispositivos móveis como laptops e smartphones no apoio aos estudos com uso 
dos recursos digitais. Por esse ângulo, podemos citar as interfaces: Jamboard®, Padlet, Gloogle forms e Kahoot.

O Google Jamboard ${ }^{\circledR}$, trata-se de quadro branco interativo que permite ao docente executar atividades online simultaneamente com seus alunos (BETTERS, 2017; GOOGLE, 2020).

Já o Google forms, o recurso possibilita a criação de diversos tipos de perguntas, nos formatos de múltipla escolha, escalas, caixas de checagem, listas suspensas etc. Permite ainda que os usuários anexem arquivos e viabiliza o uso de vídeos e imagens para ilustrar e deixar as perguntas mais elucidativas, com o uso de diversos modelos de templates, do próprio Google Forms, ou que podem ser criados pelos usuários. A plataforma disponibiliza acesso aos questionários do Google Forms em smartphones e tablets, seja para responder ou criar seus próprios questionários (MONTEIRO; SANTOS, 2019).

O Padlet corresponde a uma interface usada para construção de murais virtuais, que podem ser colaborativos ou não. Recursos digitais como o Padlet, permitem a democratização de informações ao sujeito e facilita o acesso deste a outros recursos digitais, os quais podem ser disponibilizados no ambiente único do mural. O Ambiente virtual de aprendizagem (AVA), proporcionado pelo Padlet, exerce o lugar de espaço social e digital fazendo o papel de laboratório, onde os estudantes podem entrar sempre que quiserem, bastando acessar o link disponibilizado pela própria interface (SILVA; LIMA, 2018).

O Kahoot é uma plataforma de jogo gratuita e caracteriza-se por ser online e interativa, garantindo a realização de testes de múltipla escolha (GUARDIA, 2019).

Essas plataformas permitem que espaços (diversos locais onde os estudos acontecem), tempos (cada estudante tem o seu ritmo de estudo) e formas de aprender (seja através de texto escrito, da imagem, de vídeo, de jogos didáticos etc) articulem-se aos propósitos de cada etapa da Aprendizagem Baseada em Problemas, de modo personalizado.

\section{METODOLOGIA}

Este artigo trata-se de relato de experiência acerca das potencialidades de uso das TDICs nas etapas de execução da metodologia ativa Aprendizagem Baseada em Problemas. Ele é fruto das vivências de ensino, da docente e monitor no módulo de Ciências da Vida, junto às quatro turmas das Ciências Agrárias, entre os períodos de 
janeiro e junho de 2021, ao longo do ciclo 2020.2. O referido ciclo foi executado em meio aos desafios da pandemia da COVID-19, que exigiu o uso de interfaces digitais para criação de novas possibilidades de aprendizagem durante o ensino remoto emergencial. O módulo faz parte do componente curricular e é ofertado anualmente pelo Núcleo de Graduação em Educação em Ciências Agrárias e da Terra da Universidade Federal de Sergipe, Campus Sertão.

O módulo de Ciências da Vida é componente curricular obrigatório dos cursos das Ciências Agrárias e aborda temas acerca da complexidade dos sistemas biológicos, apresentando as propriedades dos níveis de organização biológica desde as células até ecossistemas complexos. Esta proposta possibilita aos estudantes a compreensão dos mecanismos básicos evolutivos e ecológicos que regem as relações entre os seres vivos e o ambiente. O módulo de Ciências da vida é executado em seis semanas. Cada uma delas aborda questões-problemas que direcionam os discentes quanto ao conteúdo a ser estudado.

Em meio ao ensino remoto, o módulo tem sido construído com o auxílio de interfaces: Jamboard®, Padlet, Gloogle forms e Kahoot. Tanto o Jamboard $®$ como o Kahoot foram utilizados nos momentos das atividades síncronas, durante os encontros realizados na plataforma do Google Meet. Já as atividades do Padlet e Gloogle forms foram programadas para os momentos assíncronos.

Para este artigo, dos seis problemas abordados no módulo, foi escolhido o quinto, com o tema central "ecologia", para observação das experiências vivenciadas pelas turmas que possuíam entre 16 e 23 estudantes matriculados. A escolha do quinto problema deve-se ao fato de, na quinta semana de aplicação da metodologia, os alunos já estarem familiarizados com o uso das TDICs na ABP e com a forma didático-pedagógica do módulo conduzido pela professora autora deste trabalho.

Uma vez que o foco do artigo concentra-se no uso das interfaces digitais supracitadas, na $\mathrm{ABP}$, é importante relembrar as etapas para que se entenda o que é feito em cada uma delas: abertura (leitura do problema e identificação dos termos desconhecidos; levantamento de questões; busca de explicações para as questões definidas; resumo das explicações; estabelecimento de objetivos de aprendizagem); estudos individuais (respeitando os objetivos alcançados, os estudante focam no estudo de literatura científica); e fechamento (rediscussão no grupo tutorial dos avanços do conhecimento obtidos pelo grupo). 
Minutos antes da abertura, os estudantes tinham acesso ao material construído pela tutora, denominado "roteiro de atividades do problema", disponibilizado na sala de aula do Google Classroom. Este roteiro foi criado com o propósito de auxiliar os estudantes no entendimento das etapas da $\mathrm{ABP}$ e das atividades programadas com as interfaces digitais.

Para a sistematização da abertura e fechamento, utilizou-se o recurso Jamboard ${ }^{\circledR}$, o qual é empregado como mural virtual de sistematização das discussões dos grupos tutoriais, em todas as etapas da ABP. Pela versatilidade, tal interface foi usada para organizar as ideias discutidas pelos alunos durante a problematização, de maneira a possibilitar o constante debate dos conteúdos e a interação de todos os alunos no mural virtual, de modo simultâneo. Segundo Melo et al. (2019), as atividades mais visuais são reconhecidas pela sociedade como um meio de promover ao estudante um ambiente enriquecido e agradável, que permite e oportuniza a aprendizagem de várias habilidades.

Após a abertura, os estudantes tinham acesso às palestras problematizadas no Google Forms. Elas são assim chamadas porque são construídas com vídeos de especialistas do tema do problema discutido, acompanhados de questões reflexivas sobre os conteúdos do problema.

No dia seguinte à abertura, a prática laboratorial era realizada, de forma adaptada em função da pandemia da COVID-19, em ambiente virtual. Para tanto, foi utilizado o Padlet. Esta interface funcionou como um laboratório e biblioteca virtual. Tal recurso possibilitou aos discentes ter uma visão sistematizada das atividades e postagens de materiais publicados no mural (artigos científicos, livros, questionários, links para acesso ao Kahoot, vídeos, tutoriais etc.). O Google Forms também foi utilizado o momento da prática.

Durante a etapa de estudos individuais, os graduandos elaboraram resumos que faziam parte da atividade offline, denominada "quadro de referências". Neste quadro, cabia aos estudantes, antes do fechamento, organizar o resumo da pesquisa feita, por objetivo de aprendizagem definido. Além disso, cada estudante produzia slides e gravava um vídeo de até 15 minutos explicando o que havia aprendido sobre os objetivos de aprendizagem do problema ${ }^{2}$. O cumprimento desta etapa e das atividades propostas garantiam o

\footnotetext{
2 Embora os estudantes tenham trabalhado com a produção de vídeos, com uso de interfaces como o Canva, Zoom e YouTube, e também com a atividade offline, denominada quadro de referências, estas não serão analisadas neste artigo. Elas foram citadas para que o leitor veja outras atividades que também podem ser utilizadas para personalizar o ensino.
} 
aprofundamento dos estudos para o fechamento, que também foi sistematizado no Jamboard®.

Com vistas a consolidação da aprendizagem sobre a temática "ecologia" e promoção de espaço de interatividade, após o fechamento, foi utilizada a interface Kahoot. A plataforma possibilita a criação de quizzes com adição de perguntas, imagens, textos e vídeos, além de recursos sonoros e típicos de jogos, como pontuação, tempo de resposta e pódio final.

O quadro um apresenta a síntese das interfaces utilizadas durante as sete etapas da Aprendizagem Baseada em Problemas, durante o ensino remoto emergencial, que serão analisadas nos resultados e discussão.

Quadro 1-Recursos digitais utilizados em quatro turmas do módulo de Ciências da Vida, durante a execução das etapas da Aprendizagem Baseada em Problemas, no ensino remoto emergencial (2020-2021), no Campus do Sertão, da Universidade Federal de Sergipe.

\begin{tabular}{|c|c|c|}
\hline Etapas da ABP & $\begin{array}{l}\text { Interface } \\
\text { utilizada }\end{array}$ & Objetivo do uso/ou resultado esperado \\
\hline Passo $1,2,3,4,5$ e 7 & Jamboard $®$ & Sistematização dos passos da ABP. \\
\hline $\begin{array}{l}\text { Prática laboratorial } \\
\text { (passo } 6 \text { e } 7 \text { ) }\end{array}$ & Padlet & $\begin{array}{l}\text { Disponibilizar a qualquer hora os materiais da } \\
\text { prática. Recurso usado como laboratório } \\
\text { virtual. }\end{array}$ \\
\hline Palestra problematizada & Google Forms & $\begin{array}{l}\text { Ofertar aos alunos palestras problematizadas, } \\
\text { bem como avaliações das práticas laboratoriais, } \\
\text { adaptadas, por meio de questionários. }\end{array}$ \\
\hline $\begin{array}{l}\text { Aprendizagem baseada } \\
\text { em jogos }\end{array}$ & Kahoot & $\begin{array}{l}\text { Utilizar quizzes como meio de complemento } \\
\text { aos estudos e avaliação da aprendizagem após } \\
\text { o fechamento. }\end{array}$ \\
\hline
\end{tabular}

Elaboração: Silva-Júnior e Santos (2021)

Os resultados foram coletados a partir das atividades produzidas ao longo do problema cinco, referente ao tema "ecologia". As análises serão feitas com base na literatura científica pertinente. 


\section{INTERFACES DIGITAIS NAS ETAPAS DA ABP NO MÓDULO DE CIÊNCIAS}

DA VIDA

A produção do Jamboard® pelos estudantes, durante as etapas de abertura e fechamento contempla os sete passos da ABP. A sistematização dessas etapas está disposta em post-its virtuais, adicionados às colunas referentes a cada um dos passos da $\mathrm{ABP}$, como ilustra a figura um, a qual revela o mural elaborado por uma das quatro turmas, acerca do problema cinco. Cada etapa está apresentada em uma cor e as evidências de aprendizagem construídas durante a discussão dos estudantes e sistematizadas pelo secretário, mostraram o que os alunos compreenderam acerca do tema “ecologia”, desde a discussão dos conhecimentos prévios até o momento do fechamento. Embora na abertura os post-its possuam os nomes das etapas da ABP, no fechamento, o post-it central, chamado de principais pontos estudados, chamou a atenção para escrita de resultados que relacionavam os estudos individuais dos estudantes, das turmas, à construção de conceitos ocorrida durante a discussão com o grupo tutorial. Durante o debate, os discentes de todas as turmas foram capazes de identificar lacunas deixadas na etapa de estudos individuais e, ao reconhecerem o problema, criaram um post-it denominado novos pontos de estudo. 
Figura 1 - Sistematização das etapas de abertura, representado pela letra A, e fechamento sobre o problema voltado para o tema "ecologia", representado pela letra $\mathbf{B}$, utilizando o Jamboard®.

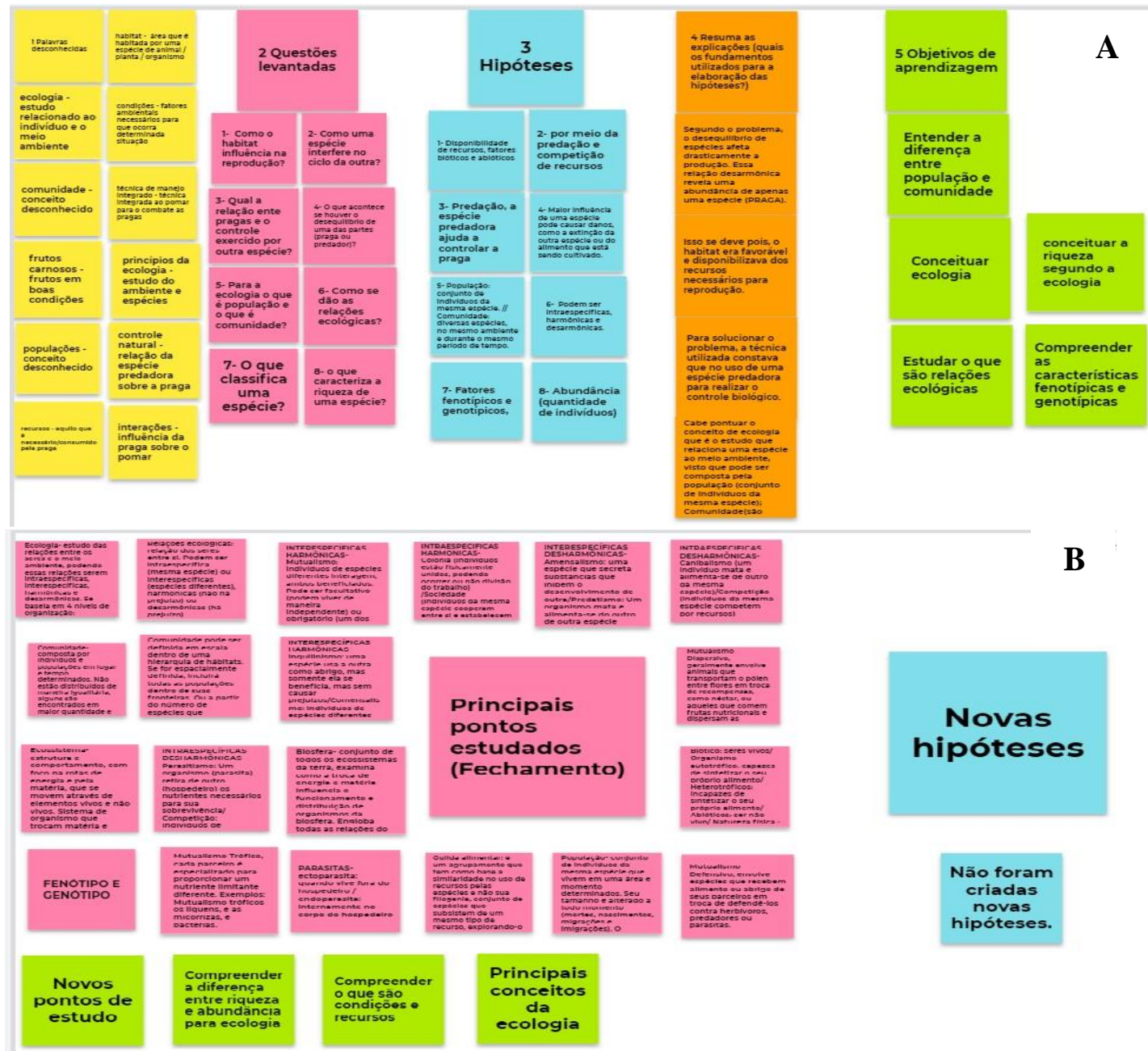

Elaboração: estudantes do módulo de Ciências da Vida (2021).

Após a sistematização dos conhecimentos prévios e definição dos objetivos de aprendizagem, todos os estudantes permaneceram com acesso ao que foi definido pela turma e podiam acessar o conteúdo sempre que desejassem. Ressalta-se que após a sistematização, durante a abertura, fica acordado que os estudantes só podem utilizar o material para consulta. A liberação de alteração do arquivo é dada apenas no fechamento, que acontece uma semana após a abertura, com o grupo tutorial. Aplicada em quatro turmas, foram observados os pontos positivos e negativos quanto ao uso do Jamboard®.

No tocante aos pontos positivos, a interface obteve papel importante na democratização e autonomia dos conhecimentos construídos durante as etapas da ABP, oferecendo aos discentes a oportunidade de visualizar sistematicamente o processo de 
construção conceitual, entre a abertura e o fechamento. O uso do recurso também gerou responsabilização nos alunos, pois estes sabiam que precisariam revelar o nível de profundidade dos estudos individuais tanto no debate, como na organização dos principais pontos estudados dispostos nos post-its do mural. Duas turmas apontaram maiores níveis de debate dos conteúdos de "ecologia" e de envolvimento com a sistematização das informações, produzindo murais ricos em conteúdos, sem tanta intervenção da tutora e com mais autonomia durante a discussão. Além disso, uma vez que todas as informações estavam expostas no mural, era possível que os grupos tutoriais acompanhassem as ideias dos colegas. Para o tutor, essa sistematização é relevante, pois permite que este acompanhe os estudantes, sem perda de informações, e realize intervenções, quando necessário, com base no que é dito e escrito no mural. Uma das dificuldades identificadas durante a abertura e fechamento refere-se ao fato do secretário nem sempre ter facilidade de organizar as ideias da discussão e ainda participar do debate. Com a visualização do mural pelo grupo no Jamboard®, foi observado que o coordenador e grupo tutorial preocupavam-se em auxiliar o secretário no registro e articulação das ideias que seriam escritas para todos. Essa forma de pensar o ensino de forma visual mostrou-se extremamente integradora.

No que diz respeito aos pontos negativos, uma das turmas demonstrou dificuldades de uso do recurso em todos os problemas, incluindo o quinto, o que foi atribuído a alguns fatores: os alunos não se interessaram pelo uso da interface desde o início do módulo até o fim; dos oito estudantes assíduos, apenas três se disponibilizavam a sistematizar as informações, como secretários, durante as aulas, enquanto os demais sempre afirmavam que o acesso da interface pelo celular era difícil; e a conexão da maioria dos estudantes sempre apresentava-se instável. Também houveram diferenças na intensidade do uso e detalhamento de informações dispostas no mural, uma vez que duas turmas foram menos produtivas no tocante ao registro dos passos da problematização no mural.

Foi possível observar que durante a abertura da $\mathrm{ABP}$, as quatro turmas conseguiam organizar as cinco etapas no Jamboard®, mas no fechamento, apenas três delas dedicaram-se à organização dos principais pontos estudados. Dessa maneira, observa-se que nem todas as turmas adaptaram-se bem à organização coletiva utilizando o recurso, principalmente no fechamento da ABP, quando o debate por vídeo chamada era priorizado e o registro das pautas na interface ficava em segundo plano. Consoante Hattie (2017), não há modelo pronto que garanta que o ensino irá apresentar impacto na 
aprendizagem dos estudantes. Todavia, existem práticas que podem ser reconhecidas como eficientes e outras que não têm esse potencial.

De todo modo, todas as turmas construíram as etapas da ABP no Jamboard®, registrando as evidências de aprendizagem relativas ao tema "ecologia", essenciais à avaliação da tutora e do monitor. Mesmo com as dificuldades de uma das turmas, a utilização deste recurso durante $\mathrm{o}$ ensino remoto possibilitou a ampliação da aprendizagem, pois contribuiu para a aprendizagem ativa e colaborativa, em que o aluno pode criar o conteúdo do seu conhecimento, fugindo do método tradicional de ensino (JARA; CASTRO, 2017; GOIS et al., 2021).

Sobre a palestra problematizada criada no Google forms, foi identificado que os alunos que assistiam a palestra e participavam das atividades propostas na interface, tinham um desempenho superior no fechamento, em relação aos que não participavam. Quanto ao feedback, o ponto mais abordado pelos discentes quanto ao uso dessa interface foi o fato da palestra ter auxiliado na compreensão de conteúdos importantes que estavam relacionados ao tema do problema. Quando perguntado às turmas em momentos de avaliação sobre os impactos da palestra problematizada para a aprendizagem, uma aluna destacou que a problematização dos vídeos e documentários estimulava a reflexão e o estabelecimento de conexões com os conteúdos científicos. Ela acrescentou que, sem a problematização, a palestra se tornava cansativa e nem sempre era possível enxergar pontos importantes do tema, apenas pela escuta, diferentemente de quando começou a ficar atenta às perguntas referentes à palestra para refletir e responder às questões. Consoante as pesquisas de Glasser (1998), que culminaram na elaboração da pirâmide de aprendizagem, os estudantes aprendem em torno de $20 \%$ quando escutam, mas cerca de $80 \%$ quando executam. Isso reflete bem os efeitos da palestra problematizada para a estudante mencionada. Ela aprendeu mais com a palestra problematizada porque precisou escutar, refletir, explicar de forma escrita, o que havia compreendido sobre os conceitos, e debater sobre o que havia estudado, durante o fechamento.

Quanto à prática laboratorial adaptada ao período de ensino remoto emergencial, utilizou-se o Padlet. A plataforma funcionou como um laboratório e biblioteca virtuais, com recursos que possibilitaram aos discentes, além de uma visão sistematizada das atividades e postagens de materiais publicados no mural, a possibilidade de baixar artigos, livros científicos, questionários, links do jogo no Kahoot, vídeos, tutoriais dos conteúdos e roteiros relacionados a atividades da problematização. Implementar tais interfaces 
dentro das metodologias ativas favorece o incentivo à autonomia uma vez que fomenta a percepção do aluno quanto à importância da própria ação (BERBEL, 2011).

Na sequência das etapas da $\mathrm{ABP}$, durante os estudos individuais, são apresentadas diversas interfaces com conteúdos de aprendizagem preparados pela tutora e pelo monitor do módulo. Parte desses conteúdos foram dispostos no Padlet como mostra a imagem abaixo (Figura 2):

Figura 2 - Padlet do problema 5 com a temática "ecologia". Captura de tela da prática 5 do módulo de Ciências da Vida.

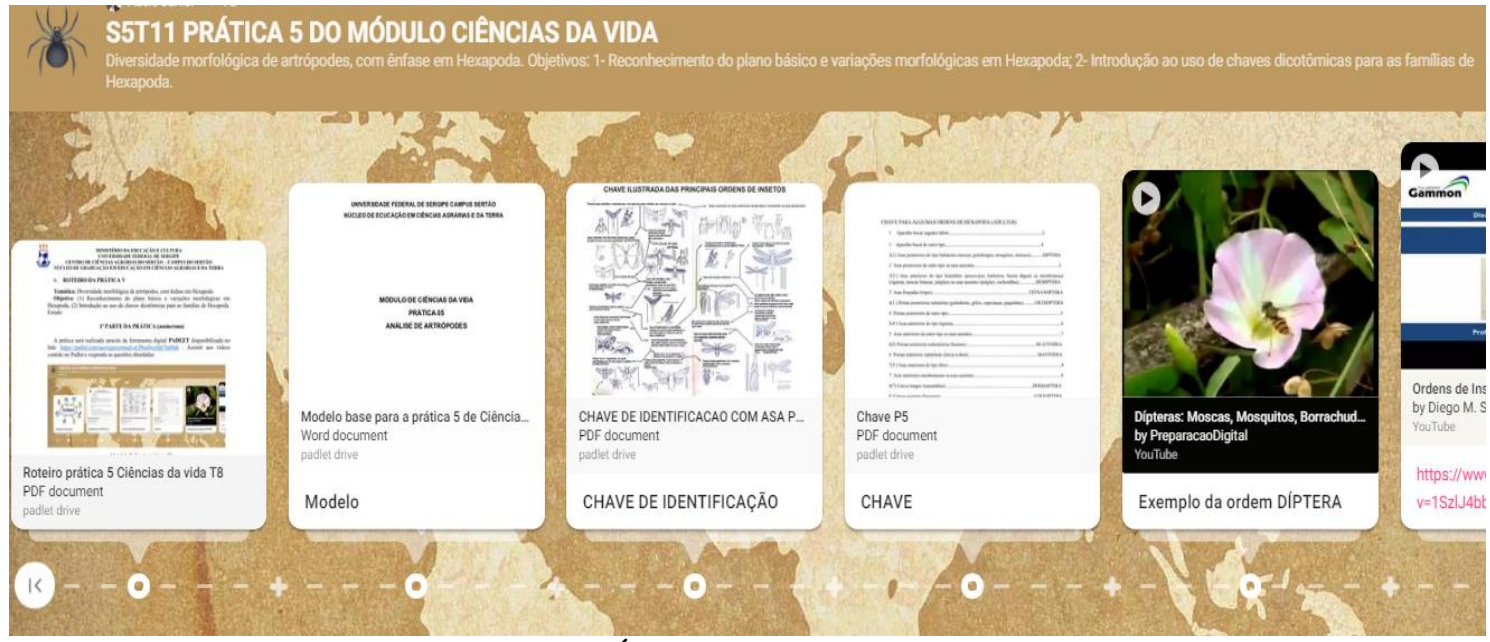

Elaboração: SILVA-JÚNIOR, 2021. Orientação: SANTOS, 2021.

Além da importância do Padlet como interface representante do laboratório virtual para os estudantes, o recurso também foi relevante à medida que se tornou o ambiente de construção dos materiais de laboratório pelo monitor, mobilizando competências de ensinar. Entende-se por competência, as ações desenvolvidas com recursos disponíveis para resolução de situações e problemas de diferentes matizes (ZABALA; ARNAU, 2020). A representação de espaço virtual onde o monitor construía e organizava os materiais que seriam trabalhados com os estudantes, de certo modo promoveu autonomia e permitiu aproximação entre os graduandos (monitor e estudantes das turmas). Acrescenta-se que, apesar do Padlet ser uma plataforma colaborativa, este não foi o foco de uso da interface durante o módulo.

A plataforma do Google Forms também foi utilizada para execução das práticas laboratoriais adaptadas. Todavia, a participação dos estduantes nas quatro turmas diversificou. A primeira turma possuía 23 alunos, mas apenas 11 realmente frequentavam as atividades, e destes, oito entregaram a prática referente ao problema cinco. Na segunda turma, com 18 alunos matriculados e oito participantes assíduos, todos os nove 
entregaram a atividade. No que diz respeito à terceira turma, esta contava com 16 alunos, mas sete eram participantes frequentes, e apenas três entregaram a atividade. Por último, a turma quatro, com 20 discentes, tinha cinco estudantes assíduos que participavam de todas as atividades. Embora não seja foco da discussão, é importante salientar que os números de matriculados e que realmente cursaram o módulo, retratam a realidade da evasão ocorrida no ensino superior durante o período da pandemia.

Ainda sobre o Google forms, entre os benefícios para a professora e monitor, destacouse a possibilidade de análise das evidências de aprendizagem. Com base nos resultados, foi possível realizar ajustes nas atividades de acordo com o diagnóstico de cada atividade aplicada, em cada turma. Somente ao conhecer e compreender o que acontece quando os processos de ensino e aprendizagem se efetivam, é que o professor torna-se capaz de fazer algo a respeito da aprendizagem dos alunos (HATTIE, 2017), reprogramando e criando atividades com base nas evidências de aprendizagem.

Uma vez que esta experiência também visa abordar pontos das interfaces no sentido da sua aplicabilidade em sala de aula, seja no modelo remoto ou presencial, outra vantagem significativa quanto ao uso dos questionários online pelo Google forms, é a economicidade dos recursos financeiros, uma vez que não é necessária a impressão das atividades, que são respondidas, via computador e smartphones, exigindo apenas acesso à internet. $\mathrm{O}$ fato do Google armazenar os questionários eletrônicos ajudou na organização dos resultados obtidos e na localização dos materiais, tanto para os discentes quanto para a professora e o monitor.

A respeito do uso do Kahoot, foi possível verificar durante os momentos síncronos o quanto os estudantes engajaram-se na atividade. $\mathrm{O}$ uso de jogos teve grande aceitação entre os alunos em sala de aula. Dos 31 alunos com participação assídua, somando as quatro turmas, 28 participaram da atividade, o que resultou em uma adesão de $90 \%$ de participação dos estudantes participantes assíduos, isto é, aqueles que compareceram em mais de $50 \%$ das atividades do problema cinco. Mesmo em idade avançada, tais atividades didáticas (jogos) detêm uma tendência a se tornar mais estratégicas e regradas além de atrativa, pois motivam, divertem e facilitam o aprendizado (GUIRRO et al., 2019). A atividade baseada em jogos gerou engajamento dos alunos em relação a novas aprendizagens, fosse pela compreensão mais clarividente, pelo poder de escolha e não obrigatoriedade em participar da atividade ou pelo interesse no jogo em si. 
No caso da experiência com o Módulo de Ciências da Vida, a utilização de jogos exigiu dos alunos habilidades e estratégias para cumprir as tarefas, promovendo aprendizado eficaz, uma vez que um dos aspectos postos em destaque como de indubitável importância no caminho da aprendizagem é a atenção seletiva, descrita por Guirro et al., (2019, p. 12) como a "habilidade que o indivíduo possui para direcionar o foco de atenção a um ponto específico no meio ambiente". Esse aspecto incorre na performance do aprendizado no tocante à existência da opção de decidir o que fazer ou não nas situações apresentadas e selecionar o que é relevante e o que é irrelevante (GUIRRO et al., 2019).

A escolha pelo uso do jogo como meio para promover aprendizagem de conteúdos sobre "ecologia", apoia-se na Teoria da Aprendizagem Significativa. Consoante Ausubel (2003), autor da Teoria, a aprendizagem significativa se dá em meio ao contato entre o conhecimento prévio do indivíduo e um recurso capaz de permitir a construção de significados. Logo, o uso do jogo durante o fechamento da ABP permitia que toda construção feita em cada etapa da metodologia ganhasse novos significados durante a execução da atividade. Consoante Silva-Pires, Trajano e Araujo-Jorge (2020), os jogos didáticos são relevantes pelas potencialidades de promoção de aprendizagem significativa, o que pode ser verificado a partir dos resultados coletados. Segundo os autores, a escolha dos jogos exige olhar crítico por parte do docente, já que a escolha do jogo deve levar em consideração o potencial do recurso nos critérios motivação e construção do conhecimento

Analisados os resultados obtidos, foi possível constatar que o uso de interfaces digitais associado às metodologias ativas facilita o aprendizado, uma vez que, as TDICs possuem a capacidade de tornar mais fácil o aprendizado de conceitos considerados como difíceis de visualizar (FABRICATORE, 2000; MITCHELL; SAVILL-SMITH, 2004).

Salienta-se ainda que, por intermédio dos recursos digitais o discente também é desafiado a tomar para si o papel de tomador de decisão (MITCHELL; SAVILL-SMITH, 2004), aspecto que se aproxima do princípio da autonomia, tão presente quando do uso de metodologias ativas na sala de aula. Outro ponto a destacar é a possibilidade de, através do uso dessas interfaces, praticar o trabalho em equipe, e, consequentemente, valorizar a colaboração entre os colegas (GROS, 2003).

As metodologias ativas têm potencial para despertar a curiosidade dos discentes (BERBEL, 2011). Se queremos estudantes proativos, é preciso começar pelo formato das aulas na graduação. Para tal, é preciso pensar na adoção de estratégias didático- 
pedagógicas que envolvam atividades mais complexas, com materiais relevantes e com avaliação constante dos resultados (MORAN, 2015).

Práticas de ensino com uso de interfaces, como as relatadas aqui, encorajam a relação entre alunos e professores, desenvolvem a reciprocidade e a cooperação entre estes. Isso tudo pode ser visto na aplicação das TDICs no módulo de Ciências da Vida mediante os frequentes feedbacks positivos dos discentes. Além desses resultados, as interfaces possibilitaram otimizar o tempo na realização das tarefas: tais tecnologias permitiram à tutora e ao monitor ganhar tempo para trabalhar em sala de aula com grupos menores e com foco na aplicação dos conteúdos estudados.

Registra-se ainda a importância das interfaces no que diz respeito à adaptação às diversas formas de aprendizagem de cada indivíduo (visual, auditiva, por meio da leitura, explicação, experiência com questionários, jogos e outras formas citadas aqui). Foi dado aos alunos uma playlist de aprendizagem para que o percurso dos estudos fosse realizado de forma eficiente, respeitando-se as habilidades e afinidades.

Hattie (2017) afirma que o ato de ensinar exige intervenções capazes de promover mudanças nos estudantes. O autor acredita que o professor, ao ter clareza dos objetivos de aprendizagem, pode proporcionar experiências significativas e desafiadoras. $\mathrm{O}$ uso das TDICs associado às metodologias ativas permite que o desafio faça parte dos processos de ensino e aprendizagem.

\section{CONSIDERAÇÕES FINAIS}

O módulo de Ciências da Vida, componente curricular obrigatório dos cursos das Ciências Agrárias, aborda temas acerca da complexidade dos sistemas biológicos. Para que o ensino e aprendizagem dos conteúdos específicos do módulo ocorram de modo eficaz, é necessário garantir que os discentes desenhem e compreendam o próprio caminho de aprendizagem. Nesse sentido, as metodologias ativas e, consequentemente, a Aprendizagem Baseada em Problemas, são fundamentais, visto que permitem ao docente propor estratégias metodológicas capazes de formar estudantes críticos, protagonistas e autônomos nos caminhos da aprendizagem.

Por este ângulo, para que a trilha de aprendizagem seja traçada pelos próprios estudantes, cabe aos professores questionar sobre quais as possíveis formas de ensinar e 
de aprender. Dentre as inúmeras formas, um dos caminhos possíveis é a personalização do ensino com uso de TDICs aplicadas às metodologias ativas.

Este relato de experiência evidencia como as TDICs podem ser aplicadas em cada etapa da ABP, possibilitando a personalização do ensino no módulo de Ciências da Vida. O uso do Jamboard®, Padlet, do Google Forms e do Kahoot facilitaram o aprendizado de conceitos admitidos nas Ciências da Vida como abstratos, tornando o estudo mais prazeroso e os conteúdos mais próximos da realidade dos estudantes. Todavia, estas são algumas dentre as várias possibilidades de tecnologias digitais que podem ser utilizadas durante o ensino remoto emergencial e após o retorno para o ensino presencial, no ensino superior.

A aprendizagem centrada no aluno, aliada a um ensino personalizado, permite que professor e estudantes construam o processo de ensino e aprendizagem de modo eficiente e eficaz. O uso de TDICs no contexto do ensino proporciona múltiplas possibilidades nas atividades educacionais que se tornam mais significativas para os estudantes. Mas, para que isso aconteça, é necessário planejamento de propostas didáticas que objetivem o "aprender a aprender", o "aprender a fazer", o "aprender a ser" e o "aprender a conviver" trabalhando, inclusive, a ligação "professor com aluno(s)"; "professor com tecnologia"; e "aluno com tecnologia".

É importante reforçar que a tecnologia não substitui a sala de aula presencial. Trabalhos como este revelam novas formas de pensar a condução das aulas com a Aprendizagem Baseada em Problemas no ensino superior, sendo as TDICs uma forte aliada nos processos de ensino e aprendizagem. Além disso, mostra possibilidades de uso de interfaces, que podem ser pensadas para a prática de ensino, tanto no formato remoto como no presencial. Dito isso, nos processos de ensino e aprendizagem com uso de metodologias ativas é possível utilizar o melhor dos dois mundos, virtual e presencial. Essa pode ser a chave para potencializar as aulas e garantir que a aprendizagem aconteça de modo eficiente e eficaz.

\section{REFERÊNCIAS}

AUSUBEL, David. Aquisição e retenção de conhecimentos: uma perspectiva cognitiva. 1. ed. Tradução de Lígia Teopisto. Lisboa: Paralelo, 2003.

BACICH, L.; MORAN, J. Metodologias ativas para uma educação inovadora: uma abordagem téorico-prática. 1 ed. Porto Alegre: Penso, 2018. 
BARROWS, H. S. A. "Taxonomy of problem-based learning methods". Medical Education. London, v. 20, n. 20, p. 81-486, 1986.

BERBEL, N. A. A. "Problematization" and Problem-Based Learning: different words or different ways? Interface - Comunicação, Saúde, Educação. Londrina. v. 2, n. 2, 1998.

BERBEL, N. A. N. As metodologias ativas na promoção da autonomia de estudantes. Semina: Ciências Sociais e Humanas. Londrina, v. 32, n. 1, p. 25-40, 2011.

BERGONSI, F. Recursos didáticos e aprendizagem estudantil no ensino superior. In: DEBALDI, B. (org.) Metodologias ativas no ensino superior: o protagonismo do aluno. Porto Alegre: Penso, 2020.

BETTERS, Elyse. O que é o Google Jamboard®, como funciona e quando você pode Comprá-lo?. Pocket-lint, 2017. Disponível em: https://www.pocket-lint.com/ptbr/gadgets/noticias/google/139279-oque-e-o-google-Jamboard®-como-funciona-equando-voce-pode-compra-lo. Acessado em 05 de julho de 2021.

DABBAGH, N.; FAKE, H.; ZHANG, Z. Student Perspectives of Technology use for Learning in Higher Education. RIED-Revista Iberoamericana de Educación a Distância. v. 22, n. 1, p. 127-152, 2019.

FABRICATORE, C. Learning and videogames: An unexploited synergy. In: INTERNATIONAL CONFERENCE OF THE ASSOCIATION FOR EDUCATIONAL COMMUNICATIONS AND TECHNOLOGY 1, 2000, Denver, Colorado., Proceedings... Farmington Hills: Learning Development Institute, 2000.

GOOGLE. Dê vida à aprendizagem com o Jamboard®. Google for education, 2020. Disponível em: https://edu.google.com/intl/ptBR/products/Jamboard®/?modal_active=none. Acesso em: 04 de julho 2021.

GOIS. A. R. da S.; GOIS. C. G. da S.; BARBOSA, P. F. C. Mapa conceitual no ensino presencial ao remoto durante a pandemia do coronavírus: relato de experiência. Research, Society and Development. v. 10, n. 3, 2021.

GLASSER, W. Choice Theory: A New Psychology of Personal Freedom. The William Glasser Institute. 1998 
GROS, B. The impact of digital games in education. First Monday, Chicago. v. 8, n. 7, 2003.

GUARDIA, J. J.; DEL OLMO, J. L.; BERLANGA, F. Innovation in the teachinglearning process: the case of Kahoot!. On the Horizon, v. 27, n. 1, p. 35-45, 2019.

GUIRRO, E. C.B. P. et al. Avaliação do uso de jogos educativos no ensino do bemestar de cães e gatos às crianças do ensino fundamental de escolas urbanas e rurais. Revista Extensão em Foco. Petrolina, n. 18, p. 15 - 31, 2019.

HATTIE, J. Aprendizagem Visível: como maximizar o impacto da aprendizagem. Tradução: Luís Fernando Marques Dorvillé; revisão técnica: Luciana Vellinho Corso. Porto Alegre: Penso, 2017.

HORN, M. B.; STAKER, H. Blended: usando a inovação disruptiva para aprimorar a educação. Tradução: Maria Cristina Gularte Monteiro; Revisão técnica: Adolfo Tanzi Neto, Lilian Bacich. Porto Alegre: Penso, 2015.

HSIAO, H. A Brief Review of Digital Games and Learning. In: THE FIRST IEEE INTERNATIONAL WORKSHOP ON DIGITAL GAME AND INTELLIGENT TOY ENHANCED LEARNING, 7, 2017, Los Alamitos, CA, USA: IEEE Computer Society, p.124-129, 2017.

JARA, V.; CASTRO, J. Desarrollo de juicio clínico con mapas conceptuales de cuidado: experiencia de estudiantes de enfermería. Enfermería Univ, v. 14, n. 4, p. 259$265,2017$.

KENSKI, V. M. Educação e Tecnologias: o novo ritmo da informação. 8 ed. Campinas: São Paulo: Papirus, 2012.

LÉVY, P. Cibercultura. Trad. Carlos Irineu da Costa. São Paulo: Editora 34, p. 260, 1999.

LÉVY, Pierre. Cibercultura. (Trad. Carlos Irineu da Costa). São Paulo: Editora 34, 2009.

MELO, S. S. de M.; OLIVEIRA, E. A. de A. Q. Educação a Distância: Desafios da modalidade para uma Educação 4.0. Revista Interdisciplinar de Tecnologias e Educação. v. 5, n. 1, p.15, nov. 2019. 
MONTEIRO, R. L. S. G.; SANTOS, D. S. A utilização da ferramenta google forms como instrumento de avaliação do ensino na escola superior de guerra. Revista Carioca de Ciência, Tecnologia e Educação (online). Rio de Janeiro. v.4, n.2, 2019.

MORÁN, J. Mudando a educação com metodologias ativas. Coleção Mídias Contemporâneas. Convergências Midiáticas, Educação e Cidadania: aproximações jovens. Campinas, v. 2, n. 1, p. 15-33, 2015.

MITCHELL, A.; SAVILL-SMITH, C. The use of computer and video games for learning: A review of the literature. 1 ed. Londres: Learning and Skills Development Agency (LSDA), 2004.

SCHUCK. J. R; Neuenfeldt, A. E. Goulart, L. K. ensino em tempos de TDIC:percepções e práticas de professores do ensino superior. Revista Prática Docente. Instituto Federal de Mato Grosso - Campus Confresa, v. 4, n. 2, p. 823-833, 2019.

SILVA, P. G.; LIMA, D. S. Padlet como ambiente virtual de aprendizagem na formação de profissionais da educação. RENOTE-Revista Novas Tecnologias na Educação. CINTED-UFRGS, v. 16, n. 1, 2018.

SILVA-PIRES, F. do E. S.; TRAJANO, V. da S.; ARAUJO-JORGE, T. C. de. A Teoria da Aprendizagem Significativa e o jogo. Revista Educação em Questão, Natal,v. 58, n. 57, p. 1-21, e-21088, jul./set., 2020.

VIANA, S. L. S. \& LOZADA, C.O. Aprendizagem baseada em problemas para o ensino de probabilidade no Ensino Médio e a categorização dos erros apresentados pelos alunos. Educação Matemática Debate. Ouro Preto, v. 4, p. 1-28, 2020.

ZABALA, A. ARNAU, L. Métodos para ensinar competências. 1 ed. Porto alegre: Penso, 2020.

Recebido em: 15/09/2021

Aprovado em: 05/10/2021

Publicado em: 10/10/2021 